\title{
Efecto del lipopolisacárido en cultivos de células dendríticas humanas y su inhibición por la polimixina B
}

\author{
Adriana Cuéllar ${ }^{1}$, Ángela Fonseca ${ }^{1}$, Alberto Gómez ${ }^{2}$ \\ ${ }^{1}$ Facultad de Ciencias, Pontificia Universidad Javeriana, Bogotá, D.C., Colombia. \\ ${ }^{2}$ Instituto de Genética Humana, Facultad de Medicina; Departamento de Microbiología, Facultad de Ciencias, \\ Pontificia Universidad Javeriana, Bogotá, D.C., Colombia.
}

Algunos estímulos de maduración utilizados en cultivos de células dendríticas, como las proteínas recombinantes obtenidas en sistemas bacterianos o los extractos proteicos de ectoparásitos, contienen lipopolisacáridos (LPS) y su presencia afecta el comportamiento de las células dendríticas en cultivo. En este trabajo se evaluó el efecto del LPS en un sistema de cultivo de células dendríticas humanas y la actividad de la polimixina B como inhibidor del efecto del LPS. Para esto, los monocitos obtenidos a partir de sangre periférica humana se diferenciaron a células dendríticas con IL-4 y GM-CSF y como estímulo de maduración se utilizó LPS o PGE2/FNT $\alpha$. La expresión de marcadores y la secreción de citocinas se evaluaron por citometría de flujo. Los resultados mostraron que la preexposición a endotoxina disminuyó la expresión de CD83, inhibió la secreción de IL-12p70, FNT $\alpha$ e IL-10 y disminuyó la secreción de IL-6 en células dendríticas. Además, la utilización de $10 \mathrm{mg} / \mathrm{ml}$ de polimixina B fue efectiva en la inhibición de la actividad de $1 \mathrm{mg} / \mathrm{ml}$ de LPS y la máxima concentración de polimixina $B$ que no afectó la morfología de las células fue de $50 \mathrm{mg} / \mathrm{ml}$. En conclusión, la polimixina B es efectiva para inhibir la actividad del LPS en los cultivos de células dendríticas.

Palabras clave: células dendríticas, citocinas, LPS, linfocitos.

Effect of lipopolysaccharides on human dentritic cell cultures and its inhibition by polymyxin B

Dendritic cells have been described as effective antigen presenting cells. Human dentritic cells are highly susceptible to lipopolysaccharide (LPS) tolerance, consisting of a differential deactivation state in which some cellular functions are impaired. LPS tolerance can be experimentally induced in vitro, in which the presence of LPS strongly affects the behavior of cultured dendritic cells. Recombinant proteins obtained from bacterial systems or protein extracts of ectoparasites containing LPS can be used as stimuli to enhance maturation processes in these cells. The present study evaluated the effect of LPS in human dendritic cell cultures, and the activity of polymyxin B as an inhibitor of the LPS effect. Dendritic cells were obtained from peripheral blood monocytes in the presence of IL-4 and GM-CSF, followed by exposure with LPS and PGE2/TNF $\alpha$. Surface markers and cytokine levels were evaluated by flow cytometry. The dendritic cells pre-exposed to single doses of endotoxin demonstrated a reduced capacity to mature, reduced CD83 expression, inhibited secretion of IL-12, TNF $\alpha, \mathrm{IL}-10$ and diminished secretion of IL-6. Furthermore, polymyxin B at $10 \mathrm{mg} / \mathrm{ml}$ inhibits LPS activity at $1 \mathrm{mg} / \mathrm{ml}$. The maximum polymyxin $B$ concentration with no effect on cellular morphology was $50 \mathrm{mg} / \mathrm{ml}$. Consequently, polymyxin B was determined to be an effective LPS inhibitor in dendritic cell cultures.

Key words: dendritic cells, cytokines, LPS, lymphocytes. 
Las células dendríticas son las células presentadoras de antígenos más potentes, no sólo por su capacidad para estimular la activación de los linfocitos $T$ a través de la presentación de antígenos en el contexto del complejo mayor de histocompatibilidad y la expresión de moléculas coestimuladoras (1-3), sino también por su capacidad para secretar citocinas que regulan la respuesta efectora Th1 o Th2 del linfocito T (4-7).

En los tejidos, las células dendríticas se encuentran en un estado inmaduro, caracterizado por una alta actividad fagocítica y su activación induce un proceso de migración a los órganos linfoides secundarios. Durante la migración, las células dendríticas entran en un proceso de maduración que involucra la pérdida de la capacidad fagocítica y aumenta sus propiedades estimuladoras para las células T CD4+ y CD8+ vírgenes $(8,9)$. La capacidad de migración de las células dendríticas se ha demostrado in vitro (10).

Se ha reportado, también, que los monocitos se pueden diferenciar a células dendríticas in vivo (11). Este proceso ha sido reproducido in vitro, utilizando citocinas como IL-4 y GM-CSF como inductores de diferenciación de monocitos a células dendríticas inmaduras y múltiples factores de maduración para obtener células dendríticas maduras como LPS, CpG, citocinas, complejos inmunes, proteínas de choque térmico y ARN de doble cadena $(2,12-16)$.

El lipopolisacárido (LPS) es un importante componente de la membrana externa de las bacterias Gram negativas y actúa como un potente activador de las células del sistema inmune. Sin embargo, se ha descrito una insensibilidad temporal de las células humanas de la inmunidad innata a retos continuos con LPS en humanos. Este fenómeno conocido como desensibilización a la endotoxina o tolerancia a LPS, se asocia con alteraciones funcionales de células del sistema monocito/macrófago y células

\footnotetext{
$\overline{\text { Correspondencia: }}$

Adriana Cuéllar, Carrera $7^{\text {a }}$ No. $43-82$, oficina 608 , Edificio Carlos Ortiz, Bogotá, D.C.

Teléfono: 320 8320, ext. 4020; fax: 320 8320, ext. 4021

acuellar@javeriana.edu.co

Recibido: 28/06/04; aceptado: 21/09/04
}

dendríticas in vivo y se puede demostrar en células aisladas in vitro $(6,17-20)$.

En varios modelos de cultivo de células dendríticas se ha demostrado que dosis únicas de LPS desde el inicio del cultivo inhiben de manera dosis dependiente, la producción de citocinas proinflamatorias y la expresión del marcador de maduración CD83+, lo cual se asocia con la disminución de su actividad endocítica. De igual manera, se encontró que estas células se comportan como fuertes estimuladores de la proliferación de linfocitos $\mathrm{T}$, pero pobres inductores de INF $\gamma$ en una reacción mixta de leucocitos $(21,22)$.

Teniendo en cuenta que muchos de los estímulos de maduración utilizados para evaluar la actividad funcional de las células dendríticas, como las proteínas recombinantes obtenidas en sistemas bacterianos o los extractos proteicos de ectoparásitos contienen LPS y que la presencia de LPS puede afectar el comportamiento de las células en cultivo, en este trabajo se buscó evaluar el efecto de LPS en un sistema de cultivo de células dendríticas humanas y la actividad de la polimixina B como inhibidor del efecto del LPS.

\section{Materiales y métodos \\ Purificación de monocitos}

Los monocitos de sangre periférica se obtuvieron de voluntarios humanos sanos, previo consentimiento escrito, a partir de $40 \mathrm{ml}$ de sangre. Se obtuvieron células mononucleares de sangre periférica en gradientes de Ficoll y se realizó una separación de monocitos con anticuerpos monoclonales anti-CD14 acoplados a perlas magnéticas, utilizando el sistema de MiniMaCs (Miltenyi). Las células obtenidas se lavaron en medio base (RPMI 1640) con $2 \%$ de suero bovino fetal (SBF). La viabilidad se evaluó con azul tripano y se realizó conteo celular. La pureza de la población se evaluó por citometría de flujo utilizando un anticuerpo anti-CD14.

\section{Diferenciación de monocitos a células dendríticas}

Todos los reactivos fueron probados para la presencia de LPS utilizando el sistema de lisado de amebocitos de Lymulus spp. (Bio Whittaker), 
siguiendo las instrucciones del fabricante. Se incubaron células CD14+ en medio completo (RPMI 1640, antibióticos, aminoácidos no esenciales, piruvato de sodio y $10 \%$ SFB) en placas de 24 pozos a una densidad de $8 \times 10^{5} / \mathrm{ml}$ en presencia de $500 \mathrm{U} / \mathrm{ml}$ de IL-4 y $50 \mathrm{ng} / \mathrm{ml}$ de GM-CSF (R\&D system, USA) durante 5 días y se verificó su morfología por microscopia de luz. El día 5 se adicionaron $5.000 \mathrm{U} / \mathrm{ml}$ de FNT $\alpha$ (R\&D Systems) y $10 \mathrm{mM}$ de PGE2 (Sigma Chemical Company) o $1 \mathrm{mg} / \mathrm{ml}$ de LPS de Escherichia coli (Sigma Chemical Company) durante 48 horas. Los sobrenadantes de los cultivos se congelaron a $-70^{\circ} \mathrm{C}$ hasta la cuantificación de citocinas. La recuperación de células dendríticas al final del cultivo se evaluó mediante conteo en cámara de Neubauer de las células no adherentes y el porcentaje de expresión de CD83 se evaluó por citometría de flujo en las células no adherentes.

Para evaluar el efecto de LPS se realizaron cultivos de células dendríticas libres de endotoxina, utilizando como estímulo de maduración $1 \mathrm{mg} / \mathrm{ml}$ de LPS en ausencia o presencia de sulfato de polimixina $B$ (Merck) en diferentes concentraciones (1, 10 y $100 \mathrm{mg} / \mathrm{ml})$.

Se utilizaron varias condiciones de cultivo en RPMI completo, para obtener al día 7 de cultivo diferentes fenotipos: 1) para obtener monocitos como control de diferenciación: cultivo en ausencia de citocinas y estímulos de maduración; 2) para obtener células dendríticas inmaduras: adición de IL-4 y GM-CSF el día 0 en ausencia de estímulos de maduración, y 3) para obtener células dendríticas maduras: cultivos en presencia de IL-4 y GM-CSF desde el día 0 con adición de LPS o PGE2 y FNT $\alpha$ el día 5 de cultivo como estímulo de maduración. Para evaluar el efecto del LPS en los cultivos de células dendríticas, se adicionó $1 \mathrm{mg}$ de LPS el día 0 de cultivo y, posteriormente, utilizando LPS (LPS/LPS) o PGE2 y FNT $\alpha$ LPS-PGE2/FNT $\alpha$ ) como estímulos de maduración en el día 5. Para determinar la máxima concentración de polimixina $B$ que no afecta la morfología celular, se utilizaron concentraciones de 10 a $100 \mathrm{mg} / \mathrm{ml}$ de polimixina $B$.

Teniendo en cuenta que una de las características de las células dendríticas diferenciadas a partir de monocitos es que pierden su capacidad de adherencia, para evaluar el porcentaje de recuperación total de células al final del cultivo, se realizó un recuento de las células no adherentes con respecto al número de células cultivadas al día $0\left(8 \times 10^{5} / \mathrm{ml}\right)$ y para determinar el porcentaje de recuperación de células dendríticas maduras se evaluó la expresión del marcador de maduración CD83+ en las células no adherentes.

\section{Citometría de flujo}

Para evaluar la expresión de marcadores de superficie se utilizó citometría de flujo de cuatro colores con anticuerpos anti CD14.APC (clon MfP9,BD Biosciences), anti HLA-DR.PerC (clon L243, BD Biosciences), anti CD86.PE (clon MO 41726, Pharmingen) y anti CD83.FITC (clon HB15e, Pharmingen), con controles de isotipo para HLA-DR (IgG2 $\alpha$.PerCP-BD Biosciences), CD86 (IgG2ß.PE-Pharmingen) y CD83 (IgG1.FITCPharmingen).

En total se colocaron $1 \times 10^{5}$ células en tubos de citometría y se incubaron por 30 minutos a $4^{\circ} \mathrm{C}$ en oscuridad con las diferentes combinaciones de anticuerpos. Se realizaron tres lavados con PBS, pH 7,2 y azida de sodio $0,1 \%$ y se resuspendieron en solución de fijación (PBS 1x, paraformaldehído al 1\%). La adquisición y el análisis de los datos se realizó usando un citómetro de flujo FACSCalibur (BD Immunocytometry Systems, USA).

La cuantificación de citocinas se realizó con un estuche comercial para detección de citocinas en sobrenadantes de cultivo por citometría de flujo (BD Biosciences), en el cual se utilizan perlas de diferentes intensidades de fluorescencia en FL3, cubiertas con anticuerpos de captura. El sistema se revela con anticuerpos anticitocinas conjugados con PE para IL-8, IL-1b, IL-6, IL-10, FNT $\alpha$ e IL-12p70. El cálculo de la concentración se realizó utilizando patrones de las diferentes citocinas en concentraciones conocidas. La sensibilidad del ensayo para cada una de las citocinas fue para IL-8 $3,6 \mathrm{pg} / \mathrm{ml}$, IL-1b $7,2 \mathrm{pg} / \mathrm{ml}$, IL-6 2,5 pg/ml, IL-10 3,3 pg/ml, TNF $\alpha$ 3,7 pg/ml e IL-12p70 1,9 pg/ml.

\section{Regulaciones éticas}

Este estudio se realizó teniendo en cuenta la resolución No. 008430 del Ministerio de Salud de 
la República de Colombia, como investigación con riesgo mínimo. Los individuos participaron en el proyecto previa firma del consentimiento escrito, y el manejo de muestras se realizó bajo las normas de seguridad (precauciones universales) en el Laboratorio de Inmunobiología y Biología Celular del Departamento de Microbiología de la Pontificia Universidad Javeriana. Además, este proyecto fue aprobado por el Comité de Ética de la Facultad de Ciencias de la Pontificia Universidad Javeriana.

\section{Análisis de los resultados}

Los resultados se muestran como el promedio de tres experimentos independientes para cada condición con desviación estándar.

\section{Resultados}

\section{Purificación de monocitos y obtención de células dendríticas}

La separación de células CD14+ mediante la utilización de perlas magnéticas permitió obtener entre el $6 \%$ y el $8 \%$ de las células mononucleares de sangre periférica con viabilidad mayor del $95 \%$. En todos los casos, el porcentaje de pureza de las células CD14+ fue mayor de $90 \%$ (figura 1A).

De acuerdo con el análisis de la expresión de marcadores, se obtuvieron células dendríticas inmaduras que fueron CD14-, CD86+, HLA-DR+ y CD83- (figura 1B) y células dendríticas maduras que fueron CD14-, aumentaron su nivel de expresión de CD86 y HLA-DR con respecto a las células dendríticas inmaduras y fueron positivas para el marcador de maduración CD83 (figura 1C). Además, la morfología celular evaluada por microscopía de luz permitió observar células grandes y con prolongaciones de la membrana, características de células dendríticas.

Los resultados mostraron que la preexposición a LPS disminuyó el porcentaje de recuperación tanto de células totales no adherentes como de células

A.

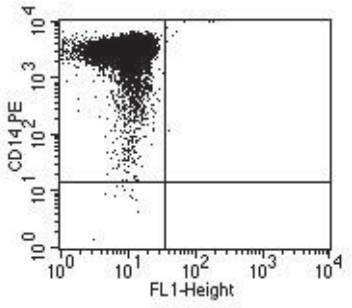

B.
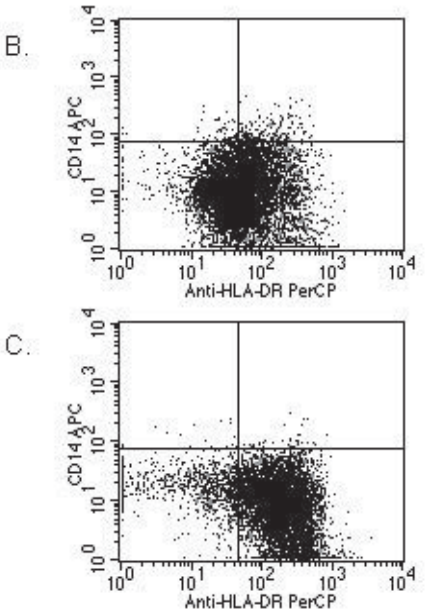
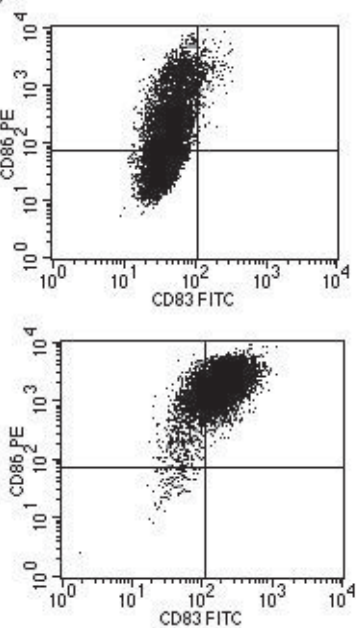

Figura 1. Dispersograma representativo de las células obtenidas de un individuo, que muestra la pureza de las células CD14+ obtenida después de la separación con perlas magnéticas (A). El fenotipo de las células al final del cultivo (día 7) para células dendríticas inmaduras (B) y células dendríticas maduras (C) evaluado mediante la expresión de CD14, HLA-DR, CD86 y CD83. 
dendríticas CD83+, utilizando los dos estímulos de maduración (figura 2).

\section{Efecto de LPS en la expresión de marcadores y secreción de citocinas}

El marcador CD14 fue negativo en células dendríticas inmaduras y maduras, y se mantuvo positivo en los monocitos. Los marcadores HLADR y CD86 fueron positivos en todos los casos y su expresión no fue alterada por la preexposición a LPS. La expresión de CD83 disminuyó en el cultivo que contenía LPS desde el día 0 y que fue madurado con LPS al día 5. Este efecto no se observó cuando se utilizó PGE2 y FNT $\alpha$ como estímulo de maduración.

Utilizando citometría de flujo, se cuantificaron las citocinas secretadas por las células al día 5 y 7 de cultivo. Al día 5 de cultivo, en condiciones libres de endotoxina, las células dendríticas inmaduras secretaron bajas cantidades de IL-8, con la adición

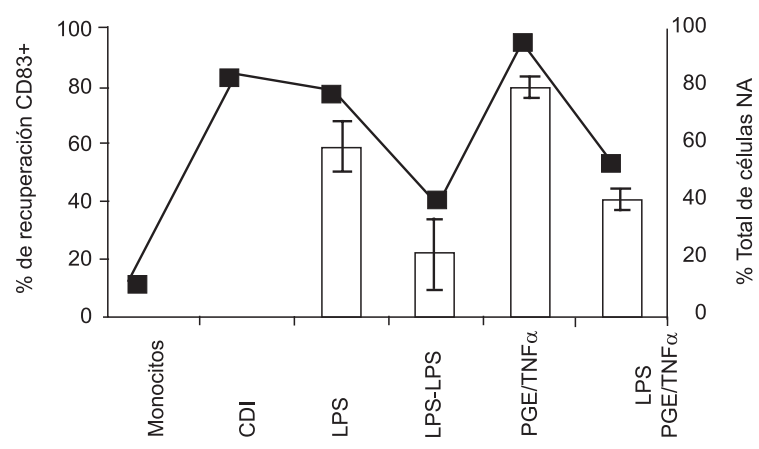

Figura 2. Porcentaje de recuperación total de células no adherentes y de células dendríticas maduras CD83+ al final del cultivo. La línea punteada muestra el porcentaje de recuperación de las células no adherentes al final del cultivo y las barras representan el porcentaje de recuperación de células dendríticas CD83+. Estos valores se obtuvieron con respecto al número de células cultivadas al día $0\left(8 \times 10^{5}\right)$. de LPS en el día 0 de cultivo, se encontraron bajas cantidades de IL-10 y altos niveles de IL-6, IL$1 \beta$ e IL-8 (cuadro 1).

Utilizando LPS como estímulo de maduración en condiciones libres de LPS al día 0 , se observó producción de IL-12p70, FNT $\alpha$, IL-10, IL-6, IL-8 y baja secreción de IL-1 $\beta$. La preexposición a LPS inhibió la secreción de IL-12p70, FNT $\alpha$ e IL-10 y disminuyó la secreción de IL-6. Los niveles de IL$1 \mathrm{~b}$ e IL-8 fueron mayores cuando se adicionó LPS al día 0 (figura 3).

Utilizando PGE2 y FNT $\alpha$ como estímulo de maduración en condiciones libres de LPS al día 0 , se observó producción de FNT $\alpha$ e IL-8. La preexposición a LPS no alteró la secreción de FNT $\alpha$, se observó una baja secreción de IL-6 y considerable aumento de IL-1b e IL-8 (figura 3).

\section{Actividad inhibidora de polimixina $B$}

Los resultados se muestran como el porcentaje de inhibición con respecto al control de estimulación con LPS, y se observa que la inhibición en la expresión del marcador de maduración CD83 aumenta de una manera dosis dependiente (figura 4). La expresión de CD86 y HLA-DR es inhibida con altas dosis de polimixina (figura 4).

Teniendo en cuenta que en condiciones libres de endotoxina se encuentra secreción de IL-12p70, FNT $\alpha$, IL-10, IL-6 e IL-8 al utilizar como estímulo de maduración LPS al día 5 de cultivo, se procedió a evaluar la secreción de estas citocinas en presencia de polimixina B. La secreción de IL-10 fue completamente inhibida en más del $98 \%$ en cada una de las diferentes concentraciones de polimixina B. En presencia de $10 \mathrm{mg} / \mathrm{ml}$ de polimixina $B$, IL-12p70 e IL-6 mostraron una inhibición cercana al $80 \%$; la secreción de IL-8 se

Cuadro 1. Citocinas secretadas por células dendríticas inmaduras (pg/ml).

\begin{tabular}{lllllll}
\hline & IL-12 $\mathbf{p 7 0}$ & FNT $\boldsymbol{\alpha}$ & IL-10 & IL-6 & IL-1 $\boldsymbol{\beta}$ & IL-8 \\
\hline PBS & 0 & 0 & 0 & 0 & $<7,2$ & $101(41)$ \\
LPS & 0 & $<3,7$ & $52,7(18,1)$ & $2.140(289)$ & $171(28)$ & $8,310(1.036)$ \\
\hline
\end{tabular}

Cuantificación de citocinas en el sobrenadante del cultivo al día 5 sin PBS o con LPS preexposición a endotoxina el primer día de cultivo. Los resultados son el promedio de tres experimentos independientes; los valores en paréntesis corresponden a la desviación estándar. 

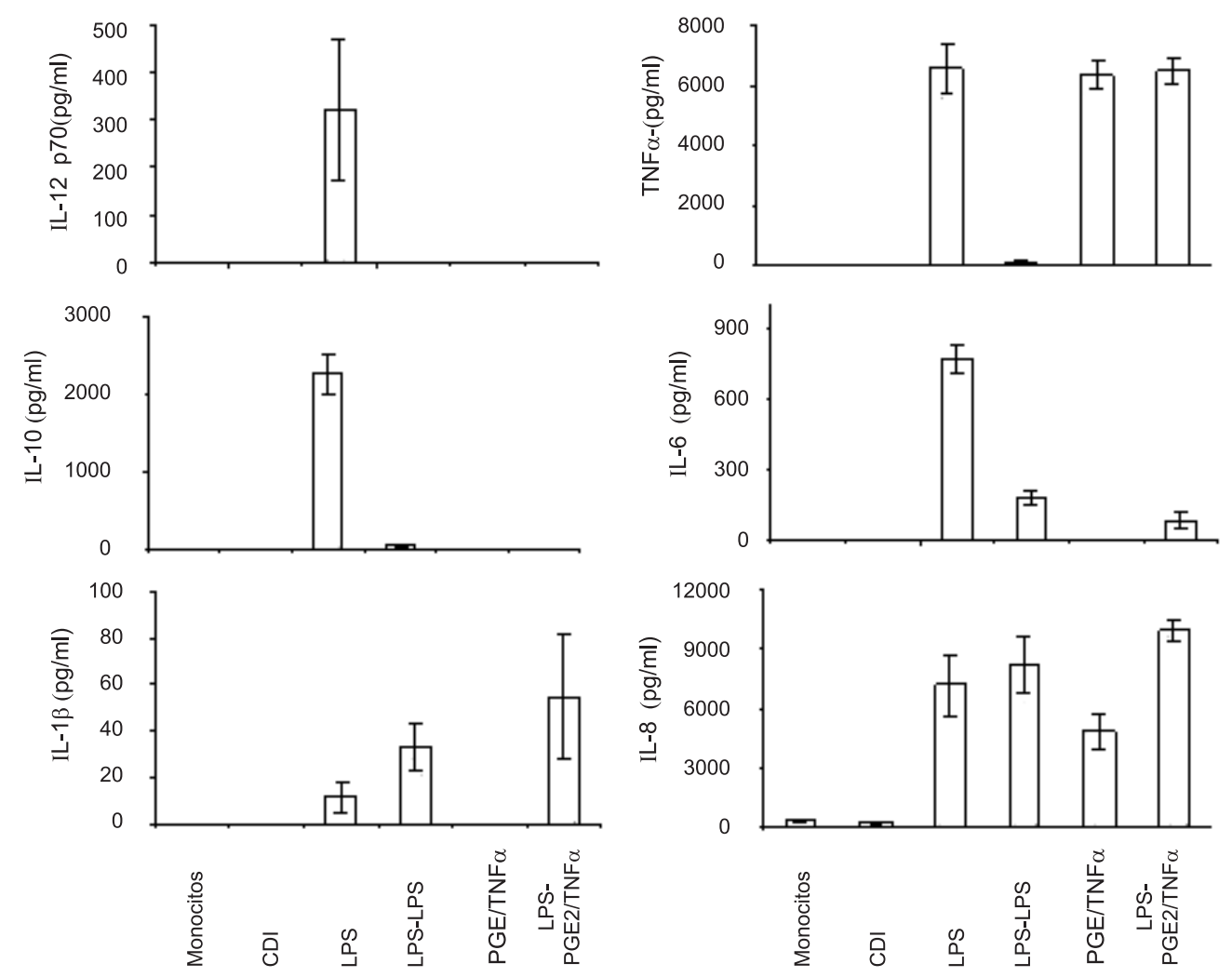

Figura 3. Cuantificación de citocinas en sobrenadante de cultivo al día 7. Los datos representan el valor de citocinas en $\mathrm{pg} / \mathrm{ml}$, cuantificadas en sobrenadante de cultivo realizado en las diferentes condiciones.

inhibió en 50\%, aproximadamente, y el FNT $\alpha$ mostró inhibición casi total. En presencia de 100 $\mathrm{mg} / \mathrm{ml}$ de polimixina $B$ se observó una inhibición casi total de todas las citocinas (figura 5).

Al analizar la morfología de las células por tamaño (FSC) y complejidad interna (SSC) por citometría de flujo, se observó que la mayor concentración de polimixina $B$ utilizada $(100 \mathrm{mg} / \mathrm{ml})$ alteró la morfología de las células, por lo cual se utilizaron diferentes concentraciones de este inhibidor para determinar la máxima concentración que no afecta la morfología de las células. Se encontró una distribución normal de las células en FSC y SSC hasta una concentración de $50 \mathrm{mg} / \mathrm{ml}$. A mayores concentraciones, el dispersograma mostró evidentes alteraciones morfológicas.

\section{Discusión}

La principal respuesta de los linfocitos T CD4+ es la producción de citocinas, las cuales se encargan de regular el tipo de mecanismo efector generado para un tipo de agresión en particular. Sin embargo, no todas las células producen el mismo patrón de citocinas. En general, los linfocitos T CD4+ se pueden diferenciar hacia linfocitos Th1 o Th2 dependiendo del microambiente encontrado en el momento de la activación linfoide, el cual depende en gran medida de las señales generadas por la célula presentadora de antígenos.

Las células dendríticas han sido consideradas las células presentadoras de antígenos por excelencia; de ellas dependen las señales iniciales inducidas por la expresión de moléculas coestimuladoras y la secreción de citocinas. Los estudios sobre fenómenos inmunes en condiciones in vitro, no necesariamente reflejan los eventos ocurridos in vivo, más aún cuando la presencia de contaminantes como el LPS afectan el comportamiento de las células en cultivo. 
Aunque los modelos descritos para la obtención de células dendríticas varían en algunas condiciones de cultivo, en general, se han utilizado citocinas como IL-4 y GM-CSF para la diferenciación de monocitos a células dendríticas con diferentes estímulos de maduración para las células, como LPS y la combinación de PGE2 y FNT $\alpha$, entre otros $(21,23-27)$.

Con el sistema de cultivo utilizado en el presente estudio se obtuvieron cultivos de células dendríticas inmaduras y maduras, y se mostró que la preexposición a LPS disminuyó el porcentaje de recuperación de células dendríticas maduras al final del cultivo. Datos similares se han reportado previamente $(22,28)$, aun cuando las condiciones de cultivo se diferencian con el presente estudio en cuanto a la adición de citocinas los días 2 y 5 de cultivo y en cuanto a que las concentraciones de LPS utilizadas fueron menores $(0,2$ y $10 \mathrm{ng} / \mathrm{ml})$.

En cuanto a la secreción de citocinas, en las células dendríticas inmaduras obtenidas al día 5 de cultivo que han estado preexpuestas a endotoxina no se encontró secreción de IL-12, aunque en otro estudio se reportó secreción de bajos niveles de IL-12 (3 pg/ml) (28). Al final del cultivo, se observó que la preexposición a LPS inhibió la secreción de IL-12, FNT $\alpha$, IL-10 y disminuyó de IL-6 $(22,29)$. A diferencia de lo previamente reportado (21), no se encontró producción de IL-12 en células maduradas con PGE2/FNT $\alpha$. Teniendo en cuenta que existen algunas diferencias en el sistema de cultivo, esto podría indicar que la adición de citocinas a diferentes días de cultivo afecta selectivamente la capacidad funcional de las células.

La polimixina B actúa como un inhibidor de los efectos de LPS como inducción de hemólisis (30), efectos tóxicos en ratón (31), respuesta mitogénica de células de bazo de ratón (32), migración de macrófagos in vitro, liberación de IL1 por monocitos y activación policlonal de linfocitos B (33).

De acuerdo con los resultados obtenidos con la utilización de polimixina $B$, se puede afirmar que hay un efecto inhibitorio de LPS dosis dependiente en la maduración de las células dendríticas.
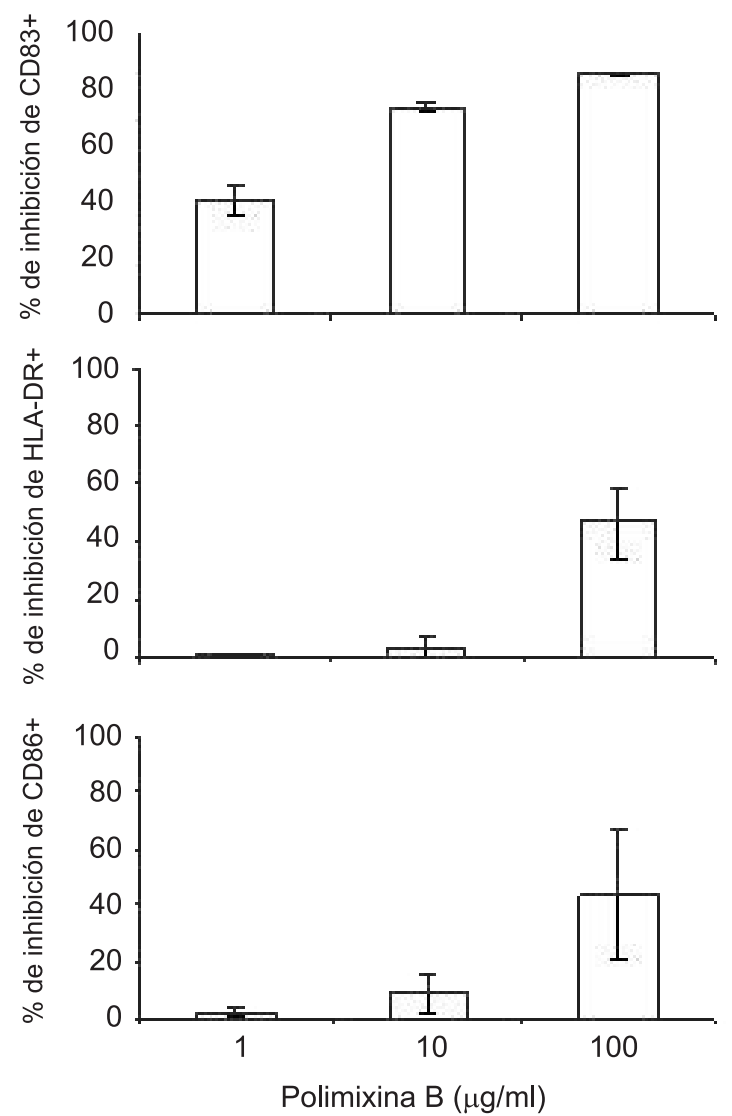

Figura 4. Inhibición de la expresión de marcadores de células dendríticas en cultivos libres de endotoxina, al adicionar 1 mg de LPS como estímulo de maduración al día 5 de cultivo en presencia o ausencia de polimixina $B$. Los resultados se muestran como el porcentaje de inhibición de la expresión del marcador en presencia de polimixina $\mathrm{B}$, con respecto a las células cultivadas en ausencia de polimixina $B$, en tres experimentos independientes.

Utilizando $10 \mathrm{mg}$ de polimixina B se logró una inhibición de $70 \%$ en la expresión de marcadores y secreción de citocinas, cuando se utilizó $1 \mathrm{mg} /$ $\mathrm{ml}$ de LPS. Además, se encontró que la máxima concentración de polimixina $B$ utilizada que no afectó la morfología de las células en cuanto a tamaño y complejidad interna fue de $50 \mathrm{mg} / \mathrm{ml}$. La concentración de $100 \mathrm{mg} / \mathrm{ml}$ de polimixina B se utilizó para evaluar el efecto de un exceso de dicho compuesto en la morfología de las células con respecto a tamaño y complejidad interna, y se observó una alteración en estos parámetros.

Los resultados obtenidos permiten concluir que la presencia de LPS en los cultivos de células 

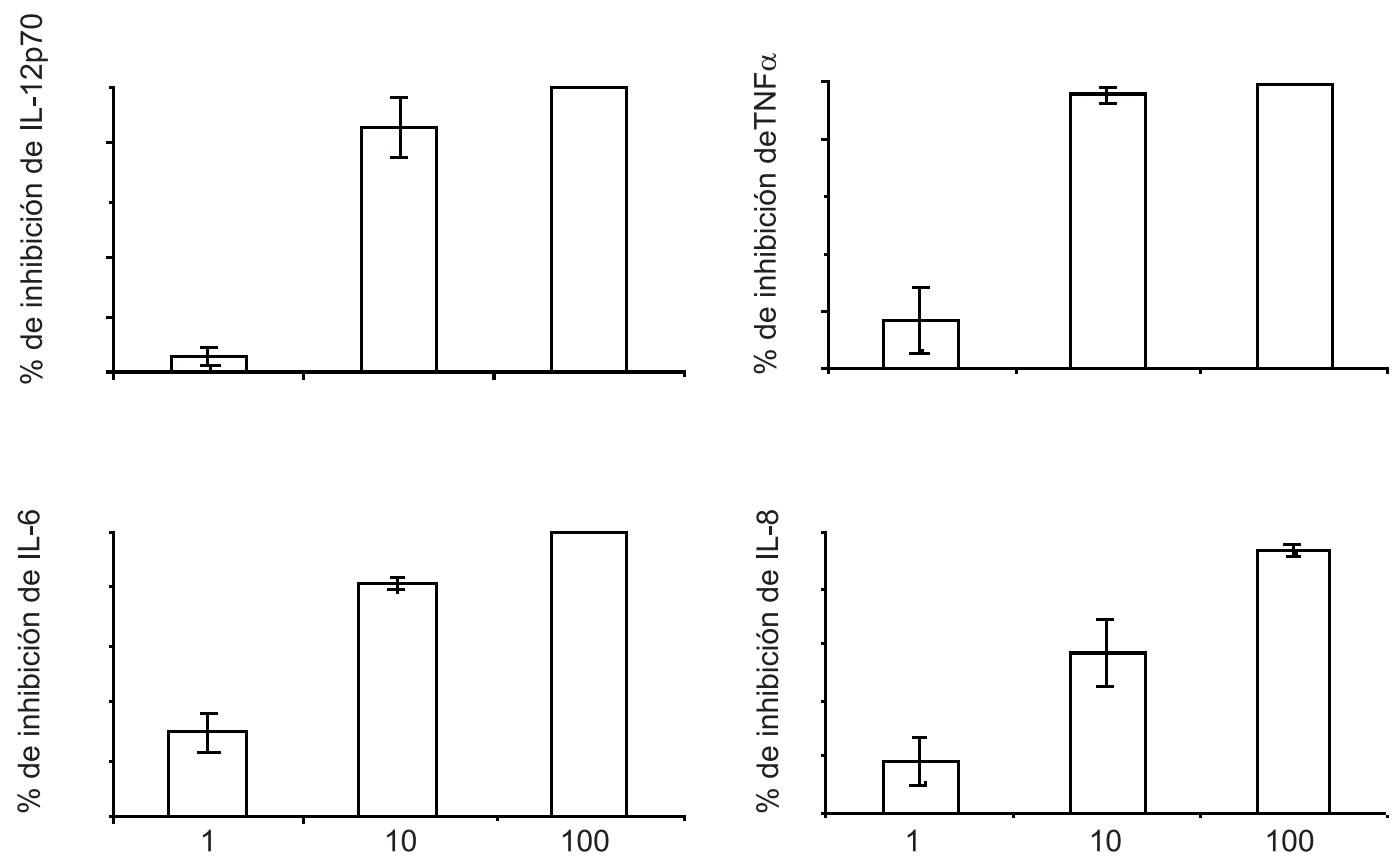

Polimixina B $(\mu \mathrm{g} / \mathrm{ml})$

Figura 5. Inhibición de la secreción de citocinas inducidas por LPS, en presencia de polimixina B. Los resultados se muestran como el porcentaje de inhibición de la concentración de citocinas, con respecto a las células cultivadas en ausencia de polimixina $B$.

dendríticas humanas afecta la capacidad de maduración de las mismas y de su actividad funcional en términos de secreción de citocinas, y que este efecto varía dependiendo del sistema de cultivo utilizado de acuerdo con lo reportado en la literatura. Además, la utilización de $10 \mathrm{mg} /$ $\mathrm{ml}$ de polimixina $\mathrm{B}$ es efectiva en la inhibición de la actividad de $1 \mathrm{mg} / \mathrm{mL}$ de LPS. La utilización de proteínas recombinantes obtenidas en sistemas bacterianos o extractos proteicos de ectoparásitos que contienen LPS como estímulos de maduración requiere la estandarización de la cantidad de polimixina $B$, utilizando un máximo de $50 \mathrm{mg} / \mathrm{ml}$, de acuerdo con la cantidad de LPS que contengan dichos estímulos.

Los cultivos de células dendríticas utilizadas en estudios de maduración de las mismas o en inducción de respuesta linfoide $T$ requieren la definición de las condiciones adecuadas para cada sistema de cultivo, ya que la presencia de contaminantes como el LPS que inducen la secreción de IL-12 podría desviar la respuesta linfoide hacia Th1. Éste ocasionaría el enmascaramiento de la respuesta que ocurre en condiciones naturales frente a diferentes estímulos. Así, en términos generales, la determinación de las condiciones de cultivo libres de LPS como la que se presenta en este informe será fundamental para evitar los sesgos en el análisis de la inmunidad innata y adquirida.

\section{Agradecimientos}

El presente trabajo fue realizado gracias al apoyo financiero de la Vicerrectoría Académica de la Pontificia Universidad Javeriana.

Un especial agradecimiento a Manuel Franco y Juanita Angel, profesores investigadores del Instituto de Genética Humana de la Pontificia Universidad Javeriana, por su colaboración en el desarrollo de este trabajo, y por su lectura crítica del manuscrito final. 


\section{Referencias}

1. Gilchrist K, Robledo $\mathbf{S}$. Las células dendríticas y su interacción con los parásitos de Leishmania. Acta Med Colomb 2003;28:117-26.

2. Sallusto F, Lanzavecchia A. Efficient presentation of soluble antigen by culture human dendritic cells is maintained by granulocyte/macrophage colony stimulating factor plus interleukin 4 and downregulated by tumor necrosis factor $\alpha$. J Exp Med 1994;179:110918.

3. Romani N, Gruner S, Brang D, Kampgen E, Lenz A, Trockenbacher B et al. Proliferating dendritic cell progenitors in human blood. J Exp Med 1994;180:8393.

4. Cella M, Facchetti F, Lanzavecchia A, Colonna M. Plasmocytoid dendritic cells activated by influenza virus and CD40L drive a potent Th1 polarization. Nat Immunol 2000;1:305-10.

5. Fearon D, Locksley R. The instructive role of innate immunity in the acquired immune response. Science 1996;272:50-4.

6. Langenkamp A, Messi M, Lanzavecchia A, Sallusto F. Kinetics of dendritic cell activation: impact on priming on Th1, Th2 and nonpolarized T cells. Nat Immunol 2000;1:311-6.

7. Moser M, Murphy K. Dendritic cell regulation of Th1Th2 development. Nat Immunol 2000;1:199-205.

8. Lanzavecchia A, Sallusto F. The instructive role of dendritic cells on $\mathrm{T}$ cell responses: lineages, plasticity and kinetics. Curr Op Immunol 2001;13:291-8.

9. Russo V, Tanzarella S, Dalerba P, Rigatti D, Rovere $P$, Villa A et al. Dendritic cells acquire the MAGE-3 human tumor antigen from apoptotic cells and induce a class I restricted T cell response. Proc Nat Acad Sci USA 2000; 97:2185-90.

10. Sarmiento L, Peña S. The Langerhans' cell. Biomédica 2002;22:462-5.

11. Randolph GJ, Inaba K, Robbiani DF, Steinman RM, Muller WA. Differentiation of phagocytic monocytes into lymph node dendritic cells in vivo. Immunity 1999;11:75361.

12. Albert ML, Jegathesan M, Darnell R. Dendritic cell maturation is required for the cross-tolerization of CD8+ T cells. Nature Immunol 2001;2:1010-7.

13. Atkins H, Davies BR, Kirby JA, Kelly JD. Polarisation of a T-helper cell immune response by activation of dendritic cells with $\mathrm{CpG}$-containing oligonucleotides: a potential therapeutic regime for bladder cancer immunotherapy. Br J Cancer 2003;89:2312-9.

14. Flohé SB, Bruggemann J, Lendemans S, Nikulina M, Meierhoff G, Flohe $\mathbf{S}$ et al. Human heat shock protein 60 induces maturation of dendritic cells versus a Th1-promoting phenotype. J Immunol 2003;170: 2340-8.

15. Fonteneau J-F, Larsson M, Somersan S, Sanders C, Münz C, Kwok W et al. Generation of high quantities of viral and tumor specific human CD4+ and CD8+ Tcell clones using peptide pulsed mature dendritic cells. J Immunol Meth 2001;258:111-26.

16. Steinman R, Turley S, Mellman I, Inaba K. The induction of tolerance by dendritic cells that have captured apoptotic cells. J Exp Med 2000;191:411-6.

17. Karp C, Wysocka M, Ma X, Marovich M, Factor R, Nutman $\mathrm{T}$ et al. Potent suppression of IL-12 production from monocytes and dendritic cells during endotoxin tolerance. Eur J Immunol 1998;28:3128-36.

18. Randow F, Syrbe U, Meisel C, Krausch D, Zuckermann H, Platzer C et al. Mechanism of endotoxin desensitization: involvement of interleukin 10 and transforming growth factor $\beta$. J Exp Med 1995;181: 1887-92.

19. Reis E Sousa C, Yap G, Schulz O, Rogers N, Schito $\mathbf{M}$, Aliberti $\mathbf{J}$ et al. Paralysis of dendritic cell IL-12 production by microbial products prevents infection induced immunopathology. Immunity 1999;11:637-47.

20. Wysocka M, Robertson M, Riemann H, Caamano J, Hunter C, Mackiewicz A et al. IL-12 supression during experimental endotoxin tolerance: dendritic cells loss and macrophage hyporesponsiveness. J Immunol 2001; 166:7504-13.

21. Rieser C, Böck G, Klocker H, Bartsch G, Thurnher M. Prostaglandin E2 and tumor necrosis factor a cooperate to activate human dendritic cells: synergistic activation of interleukin 12 production. J Exp Med 1997; 186:1603-8.

22. Rieser C, Papesh C, Herold M, Böck G, Ramoner $\mathbf{R}$, Klocker $\mathbf{H}$ et al. Differential deactivation of human dendritic cells by endotoxin desensitization: role of tumor necrosis factor $\alpha$ and prostaglandin E2. Blood 1998;91: 3112-7.

23. Shortman K, Liu Y. Mouse and human dendritic cells subtypes. Nat Rev Imunol 2002;2:151-61.

24. Sallusto F, Cella C, Danieli C, Lanzavecchia A. Dendritic cells use macropinocytosis and the mannose receptor to concentrate macromolecules in the major histocompatibility complex class II compartment: down regulation by cytokines and bacterial products. J Exp Med 1995;182:389-400.

25. Thurnher M, Papesh C, Ramoner R, Gastl G, Böck C, Radmayr $\mathrm{H}$ et al. In vitro generation of CD83+ human blood dendritic cells for the active tumor immunotherapy. Exp Hematol 1997;25:232-7.

26. Cella M, Salio M, Sakakibara Y, Lancen H, Julkunen I, Lanzavecchia A. Maturation, activation, and protection of dendritic cells induced by double-stranded RNA. J Exp Med 1999;189:821-9. 
27. Zhou I, Tedder T. CD14+ blood monocytes can differentiate into functionally mature CD83+ dendritic cells. Proc Natl Acad Sci USA 1996;93:2588-92.

28. Xie J, Quian J, Wang S, Freeman M, Epstein J, Yi Q. Novel and detrimental effects of lipopolysaccharide on in vitro generation of immature dendritic cells: involvement of mitogen-activated protein kinase p38. J Immunol 2003; 171:4792-800.

29. Verhasselt V, Buelens C, Willems F, De Groote D, Haeffner-Cavaillon N, Goldman M. Bacterial lipopolysaccharide stimulates the production of cytokines and the expression of costimulatory molecules by human peripheral blood dendritic cells: evidence for a soluble CD14-dependent pathway. J Immunol 1997;158:2919-25.
30. Neter E, Gorzynski E, Westphal O, Luderitz O. The effects of antibiotics on enterobacterial lipopolysaccharides (endotoxins), hemagglutination and hemolysis. J Immunol 1958;80:66-72.

31. Rifkind D. Neutralization of the Shwartzman reactions by polymyxins B. J Immunol 1967;99:564-9.

32. Jacobs D, Morrison D. Dissociation between mitogenicity and immunogenicity of TNP-lipopolysaccharide, a T-independent antigen. J Exp Med 1975; 141:1453-8.

33. Duff G, Atkins E. The inhibitory effect of polymyxin B on endotoxin-induced endogenous pyrogen production. J Immunol Meth 1982;52:333-40. 